\title{
Difficulties in the Management of Systemic Autoimmune Diseases in Saint-Louis Du Senegal through the Analysis of a Series of 70 Observations
}

\author{
Diatou G. Dia1, Amadou D. Dia1, Nafissatou Diagne², Awa C. Ndao², Cheikh T. Tall ${ }^{3}$, \\ Blaise M. Ngouamba ${ }^{4}$
}

${ }^{1}$ Gaston Berger Saint-Louis University, Dakar, Senegal

${ }^{2}$ Cheikh Anta Diop University, Dakar, Senegal

${ }^{3}$ Saint-Christopher University, Dakar, Senegal

${ }^{4}$ Department of Internal Medecine, Saint-Louis, Sénégal

Email: diadiami@yahoo.fr, amadou-diop.dia@ugb.edu.sn, nafissatoud@hotmail.com,

ndaoawacheikh@gmail.com, cheikhttall@yahoo.fr,bm.ngouamba@gmail.com

How to cite this paper: Dia, D.G., Dia, A.D., Diagne, N., Ndao, A.C., Tall, C.T. and Ngouamba, B.M. (2021) Difficulties in the Management of Systemic Autoimmune Diseases in Saint-Louis Du Senegal through the Analysis of a Series of 70 Observations. Open Journal of Internal Medicine, 11, 258-264.

https://doi.org/10.4236/ojim.2021.114022

Received: October 16, 2021

Accepted: December 21, 2021

Published: December 24, 2021

Copyright $\odot 2021$ by author(s) and Scientific Research Publishing Inc. This work is licensed under the Creative Commons Attribution International License (CC BY 4.0).

http://creativecommons.org/licenses/by/4.0/

\begin{abstract}
Introduction: Systemic Autoimmune Diseases (SAID) long considered very rare in Africa are increasingly the subject of publications. The objective of this work is to identify the difficulties in the management of these pathologies in an internal medicine department in northern Senegal by analyzing the epidemiological, clinical-biological, therapeutic and evolutionary aspects of SAID. Methods: This was a descriptive cross-sectional study carried out in the internal medicine department of the Saint-Louis University Hospital Center. Included were all the files of patients followed in outpatient and/or hospitalization for autoimmune diseases according to the criteria of the American College of Rheumatology, during the period from January 2017 to December 2020. The data were analyzed using SPSS software version 21.0. As the study was descriptive, no statistical test was performed. Results: Out of 3800 patients, 70 presented SAID, i.e. a hospital prevalence of $1.8 \%$. Polyarthritis was the first reason for consultation in $97 \%$ followed by skin manifestations in $8 \%$. The patients had positive anti-nuclear autoantibodies in $88 \%$ of cases. Rheumatoid arthritis was the predominant condition (71\%) followed by systemic lupus erythematosus (SLE) (15\%) and undifferentiated autoimmune diseases in $10 \%$. Eleven percent (11\%) of patients had an associated autoimmune disease. Corticosteroids were used in the treatment of these conditions in $97 \%$ of cases and methotrexate was the most prescribed immunosuppressant (54\%). Thirty-two percent (32\%) of patients are lost to follow-up. Con-
\end{abstract}


clusion: SAID are diverse and under diagnosed; they are characterized by diagnostic delay above all linked to access to specialists and sometimes to the high cost of paraclinical examinations, in particular immunology. Treatment remains based primarily on corticosteroid therapy and conventional immunosuppressants in the face of the unavailability of biotherapies.

\section{Keywords}

Systemic Autoimmune Diseases, Polyarthritis, Systemic Lupus

Erythematosus, Saint-Louis Du Senegal

\section{Introduction}

Autoimmune diseases constitute a heterogeneous group of pathologies, affecting $5 \%$ to $8 \%$ of the world population [1]. These SAID result from a dysfunction of the immune system leading to a breakdown in self-tolerance. This usually results in the production of autoantibodies leading to organ damage [1] [2].

In sub-Saharan Africa, autoimmune diseases in general are the subject of limited work on hospital series. They are under diagnosed due on the one hand to the variability of their modes of disclosure, and on the other hand to the insufficiency of the technical platform. However, since the last decade, SAID are now more and more described in Africa and their prevalence is clearly increasing [1] [3] [4] [5].

This original work in Saint-Louis, Senegal is part of a process of highlighting the issue of the management of these pathologies in developing countries. The objective of this work is to describe the epidemiological, clinical, biological and therapeutic aspects of cases of SAID encountered in the internal medicine department of the CHU de Saint-louis in order to improve their diagnosis and management.

\section{Methods}

This was a descriptive cross-sectional study carried out in the internal medicine department of the Saint-Louis regional hospital center. It was carried out on the basis of the medical files of patients received from January 1, 2017 to December 31,2020 , i.e. a period of 4 years.

For each patient listed, the diagnosis of SAID was made using the American College of Rheumatology (ACR) classification criteria [6] [7].

All the files of patients received in outpatient and hospitalization for one or more of these organ-specific or non-specific SAID were included. Incomplete records were not included in the study.

For data collection: the following variables were collected:

- Epidemiological: age, sex, profession,

- Clinical: reasons for consultations, history, clinical manifestations,

- Paraclinical: inflammatory assessment, immunological assessment requested 
depending on the clinical orientation, it could be, depending on the case, biological examinations and/or imaging.

Biology: blood count, sedimentation rate, $c$ reactive protein, 24 hour proteinuria, muscle enzymes, rheumatoid factor, autoantibodies, histology.

Imaging: skeletal $\mathrm{x}$-ray, chest $\mathrm{x}$-ray, respiratory function tests, cardiac Doppler echocardiography, chest CT scan.

- Therapeutics: prescribed molecules (corticosteroids, synthetic antimalarials, immunosuppressants).

Data were analyzed using SPSS software version 21.0. As the study is descriptive, no statistical test was performed. Frequency calculations were carried out for each of the modalities of the variables studied.

\section{Results}

7 files were excluded from the study because the anamnestic and paraclinical data were incomplete.

\subsection{Epidemiological Data}

Out of 3800 patients received, 70 patients had a systemic autoimmune disease, i.e. a hospital prevalence of $1.8 \%$.

The average age of our patients was 40.12 years with extremes ranging from 7 to 69 years. There were 61 women and 9 men, i.e. a male/female sex ratio of 0.12 .

\subsection{Diagnostic Data}

The mean duration of the disease was 38.6 months with the extremes of 1 and 180 months.

A history of personal or familial autoimmune disease was observed in $4.28 \%$ of the patients in our series. Type 2 diabetes was noted in $2.86 \%$ of cases.

The semiological manifestations of autoimmune diseases were dominated by joint signs (97\%), cutaneous (8.58\%), renal damage (4\%), Reynaud's phenomenon, seritis and muscle damage (2.86\%).

Table 1 gives the distribution of patients according to the manifestations present at diagnosis. There was a nonspecific inflammatory response syndrome in $54 \%$ of our cohort. Other laboratory abnormalities were demonstrated on the blood count (Table 2).

Rheumatoid arthritis was the most common autoimmune diseases (71.4\%). Table 3 gives the distribution of patients according to the type of autoimmune diseases diagnosed. In our series, $11 \%$ of the patients presented with another associated autoimmune disease: 3 cases of Hashimoto's thyroiditis, 2 cases of Sjögren's Syndrome and 3 cases of Systemic Sclerosis (SSc).

Rheumatoid factor and antinuclear antibodies returned positive in $48.57 \%$ and $88.8 \%$ of patients, respectively. Anti cyclic citrinullated peptide (CCP) autoantibodies were positive in $82 \%$ of RA cases. The other specific antibodies associated for patients with SLE, anti-native DNA (3/7), anti-Sm (7/17), anti-RNP 
Table 1. Distribution of patients according to clinical manifestations.

\begin{tabular}{ccc}
\hline Type of clinical manifestations & Number & Percentage \\
\hline Articular & 68 & 97 \\
Cutaneous & 6 & 8.58 \\
Rénal & 3 & 4.28 \\
Muscular & 2 & 2.86 \\
Gyneco-obstetrics & 4 & 5.71 \\
Reynaud phenomenon & 2 & 2.86 \\
Pulmonary & 2 & 2.86 \\
Serite & 2 & 2.86 \\
Lymphadenopathy & 3 & 4.28 \\
\hline
\end{tabular}

Table 2. Inflammatory assessment data for the study population.

\begin{tabular}{cccc}
\hline & Minimum & Maximum & Average \\
\hline Hemoglobin $(\mathrm{g} / \mathrm{dL})$ & 7.8 & 16.1 & 11.37 \\
Mean corpuscular volum $(\mathrm{fL})$ & 29.8 & 100 & 80.29 \\
Mean corpuscular hemoglobin content $(\mathrm{pg})$ & 19.3 & 37 & 28.27 \\
Leukocyte $\left(10^{3} / \mu \mathrm{L}\right)$ & 3.21 & 21.2 & 7.75 \\
Lymphocyte $\left(10^{3} / \mu \mathrm{L}\right)$ & 3.4 & 5.13 & 2.22 \\
Platelets $\left(10^{3} / \mu \mathrm{L}\right)$ & 158 & 527 & 309.57 \\
First hour sedimentation rate & 37 & 101 & 44.67 \\
Second hour sedimentation rate & 23 & 120 & 79.23 \\
CReactive Protein & 4 & 213 & 34.12 \\
\hline
\end{tabular}

$\mathrm{Hb}=$ hemoglob.

Table 3. Distribution of patients by diagnosis.

\begin{tabular}{ccc}
\hline Diagnosis & Number & Percentage \\
\hline Systémic Lupus & 11 & 15 \\
Rhumatoid arthritis & 50 & 71 \\
Systemic scleroderma & 3 & 4.2 \\
Sjogren Syndrome & 2 & 2.8 \\
Indéterminate connectivity & 7 & 10 \\
Mixed Connectivity & 1 & 1.5 \\
Dermatomyositis & 1 & 1.5 \\
\hline
\end{tabular}

(4/17), anti-SSA (7/17) and anti-Scl 70 antibody in 3 SSc patients.

\subsection{Therapeutic and Evolutionary Data}

Treatment, depending on the pathology, consisted of corticosteroids in all pa- 
tients. The use of hydroxychoroquine affected $30 \%$ of patients. The immunosuppressants used were Methotrexate (54\%), Salazopyrine (14\%) and Azathioprine (11\%).

Most of the patients followed were stabilized during the controls (56\%).

Fifty-six per cent of the patients followed were stabilized during the checks (thirty-six to one year of follow-up, twenty-eight to two years and twenty-two to three years and more). Five patients were lost to follow-up on the fourth check-up. However, $32 \%$ of patients were lost to follow-up after one year of follow-up. Three deaths (4\%) were recorded during follow-up.

\section{Discussion}

In sub-Saharan Africa, SAID are pathologies of young women [1] [3] [4] [5] [8]. Our series has confirmed this with the predominance of women and an average age of 40.12 years.

The reasons for consultation were dominated by osteo-articular pain, ie $97 \%$ in our study. Our figures are similar to those in the literature [4] [5] [8].

The late consultation period in our series (38.6 months on average) is also a characteristic of the African series [9] [10] [11] [12] [13]. In fact, apart from their relative scarcity, the management of SAID in our regions comes up against several difficulties, including a lack of knowledge of these pathologies and a lack of specialists who are few in number [14] [15] [16] [17]. This explains the long consultation times in a specialized environment.

The long diagnostic delay observed in general similar in the various countries reinforces this ignorance of the pathology by the practitioners who confuse these autoimmune pathologies with various other tropical pathologies due to the clinical polymorphism. In fact, due to the clinical polymorphism and the preponderance of general signs, in particular fever, a good number of cases are treated as malaria or typhoid fever by some city practitioners [9] [13].

In our study, $87 \%$ of patients were able to benefit from an immunological assessment, which is lower compared to European and Maghreb studies [5] [6]. Indeed, the high cost of immunological assays limits their systematic practice. In the study by Leye et al. in Dakar, $59.9 \%$ of patients underwent at least one immunological examination [8]. It should also be noted that these operations are carried out very late, which causes the diagnosis and consequently the treatment to be erroneous.

In terms of frequency, Rhumatoid Arthritis was dominant followed by systemic lupus. Diousse found a predominance of systemic lupus [16]. This difference is explained through patient recruitment; a dermatology department served as a framework for Diousse unlike our versatile internal medicine department. The majority of African series find RA as the dominant autoimmune diseases [3] [4] [5] [8].

Regarding treatment, in our study methotrexate was prescribed the most, followed by salazopyrine and azathioprine. It is important to note that the thera- 
peutic approach to MAIS varies depending on the type of autoimmune diseases and its stage of development (existence of serious visceral damage), or the need to refine the diagnosis with the dosage of antibodies. Treatment is another major problem in sub-Saharan Africa faced with the insufficiency of available therapeutic means, in particular the absence of the possibility of recourse to biotherapies, intravenous immunoglobulins and plasma exchanges. The treatment remains empirical based above all on prolonged corticosteroid therapy and conventional DMARDs (abbreviation in English: cs DMARD for conventional synthetic Disease Modifying Anti-Rheumatic Drug) [18]. The availability and accessibility of biotherapies therefore constitutes another challenge to be taken up in order to improve the management and prognosis of our patients [2] [19].

In terms of follow-up, the number of lost to follow-up is high (32\%), which prevents an accurate evaluation of the treatments, and of the overall prognosis of these conditions [2].

\section{Conclusion}

Systemic autoimmune diseases are increasingly studied in sub-Saharan Africa and pose a challenge for practitioners. However, better knowledge of these pathologies to reduce consultation times, improvement of the technical platform with accessibility of the immunological assessment and finally the availability of biotherapies are necessary to improve the management of these pathologies.

\section{Conflicts of Interest}

The authors declare no conflicts of interest regarding the publication of this paper.

\section{References}

[1] Konan, M., Binan, Y., Acko, U.V., Bita, D., Ouattara, R. and Toutou, T. (2019) Caractéristiques des maladies auto-immunes: Analyse d'une série de 45 patients. Revue International des Sciences Médicales, 21, 306-311.

[2] Kâ, M.M., Diop, M.M., Lèye, A., Lèye, Y., Touré, P.S., Berthé, A., Dia, D.G., Dioussé, P. and Diop, B.M. (2017) Problématique des maladies auto immunes en Afrique. Revue Africaine de Médecine Interne, 4, 7-8.

[3] Kane, B.S., Ndongo, S., Ndiaye, A.A., Djiba, B., Niasse, M., Diack, N., Ndao, A.C., Fall, B.C., Gning, S. and Pouye, A. (2016) Maladie systémique en médecine interne contexte africain: Aspects épidémiologiques et classification. La Revue de Médecine Interne, 37, A37. https://doi.org/10.1016/j.revmed.2016.04.237

[4] Ouedraogo, D.-D., Korsaga-Some, N., Zabsonne Tiendrebeogo, J., Tieno, H., Kabore, H., Niamba, P. and Drabo, J. (2014) Connective Tissue Diseases in Hospital Practice in Ouagadougou (Burkina Faso). Médecine et santé Tropicales, 24, 271-274. https://doi.org/10.1684/mst.2014.0348

[5] Louzir, B., Othmani, S. and Ben Abdelha dh, N. (2003) Le lupus érythémateux systémique en Tunisie. Etude multicentrique nationale. A propos de 295 observations. La Revue de Médecine Interne, 24, 768-774.

https://doi.org/10.1016/S0248-8663(03)00250-9 
[6] Hochberg, M.C. (1997) Updating the American College of Rheumatology Revised Criteria for the Classification of Systemic Lupus Erythematosus. Arthritis \& Rheumatology, 40, 1725. https://doi.org/10.1002/art.1780400928

[7] Sibilia, J. (2007) How to Define and to Classify Inflammatory Systemic Diseases? Revue du Rhumatisme, 74, 714-725. https://doi.org/10.1016/j.rhum.2007.07.003

[8] Lèye, Y.M., Ndiaye, N., Diack, N.D., Ndour, M.A., Fall, B.C., Kâ, W., Devokolot, J.D.G., EL Fajri, S., Bahati, A., Niass, A., Fall, M., Touré, P.S., Diop, M.M., Kâ, M.M. and Léye, A. (2017) Aspects épidémiologiques et diagnostiques des connectivites au service de Médecine Interne du CHUN de Pikine: Analyse de 287 observations. RAFMI, 4, 22-25.

[9] Ouedraogo, D.D., Korsaga-Some, N., Zabsonne Tiendrebeogo, J., et al. (2014) Les connectivites en pratique hospitalière à Ouagadougou (Burkina Faso). Médecine et Santé Tropicales, 24, 271-274.

[10] Niasse, M., Kane, B.S., Ndiaye, A.A., et al. (2017) Severity of the Rheumatoid Arthritis in Sub-Saharan Africa: Study of 403 Senegalese Observations. Open Journal of Internal Medicine, 7, 151-159.

[11] Malemba, J.J. and Mbuyi-Muamba, J.M. (2008) Clinical and Epidemiological Features of Rheumatic Diseases in Patients Attending the University Hospital in Kinshasa. Clinical Rheumatology, 27, 47-54. https://doi.org/10.1007/s10067-007-0650-x

[12] Ntsiba, H., Ngandeu-Singwe, M. and Mbuyi-Muamba, J.M. (2010) Les connectivites en Afrique centrale. Revue du Rhumatisme, 77S, 199.

[13] Guerne, P.A. (2013) Manifestations ostéo-articulaires dans les connectivites. Revue Médicale Suisse, 9, 542-548.

[14] Fall, S., Pouye, A., Ndiaye, F.S., Ndongo, S., Leye, Y. and Dioumet, L. (2011) Initial Presentation of Systemic Lupus Erythematosus in Senegal. Medecine d Afrique Noire, 58, 156-160.

[15] Niang, S.O., Coumé, M., Ndiaye, M., Diop, A., Diatta, B.A., Diallo, M., et al. (2011) The Scalp Involvements in the Connective Tissue Diseases. JCDSA, 1, 95-98. https://doi.org/10.4236/jcdsa.2011.13014

[16] Diousse, P., Berthé, A., Done, H., Touré, P.S., Bammo, M., Seck, F., Guèye, N., Diop, M.M., Faye, F.A., Dieng, M.T., Diop, B.M. and Kâ, M.M. (2017) Profil épidémio clinique des maladies auto-immunes systémiques dans le service de Dermatologie. Revue Africaine de Médecine Interne, 4, 18-21.

[17] Gabay, C. and So, A. (2013) Les connectivites, une affaire de spécialistes? Revue Médicale Suisse, 9, 539-540.

[18] N'Soundhat, N.E.L. and Honoré, N. (2020) Les Maladies Auto Immunes et de Système au Service de Rhumatologie du Centre Hospitalier Universitaire de Brazzaville. Health Sciences and Disease, 21, 138-142. https://www.hsd-fmsb.org

[19] Ndongo, S., Pouye, A., Lekpa, F.K., Bihéhé, D.M., Tiendrebeogo, J., Ndao, A.C., Ka, M.M. and Moreira Diop, T. (2012) Problématique du traitement de fond des rhumatismes inflammatoires en Afrique subsaharienne: Évolution à six mois de 205 patients sénégalais atteints de polyarthrite rhumatoïde. Médecine et Santé Tropicales, 22, 385-389. 